\title{
11
}

\section{Eliciting Accurate Consumption Responses from Vulnerable Populations}

\author{
Lennart Kaplan, Utz Pape and James Walsh
}

\section{The Data Demand and Challenge}

Accurate data on the key economic variables affecting people who have been forcibly displaced, such as consumption and assets, is essential to understanding their situation and to developing evidence-based policies to support them. Poor information or data inaccuracies can lead to flawed diagnostics and impact assessments, resulting in inefficient use and a waste of limited resources. In the context of displacement, consumption

\footnotetext{
L. Kaplan

University of Göttingen, Göttingen, Germany

Heidelberg University, Heidelberg, Germany

U. Pape $(\bowtie) \cdot$ J. Walsh

World Bank, Washington, DC, USA

e-mail: upape@worldbank.org

J. Walsh

e-mail: james.walsh@nuffield.ox.ac.uk

(C) International Bank for Reconstruction and Development/The World Bank 2020

J. Hoogeveen and U. Pape (eds.), Data Collection in Fragile States,

https://doi.org/10.1007/978-3-030-25120-8_11
} 
data is particularly important because malnutrition is rife and mortality rates are high, and interventions using consumption data are needed to support the immediate basic needs of vulnerable populations.

In previous High Frequency Survey (HFS) survey rounds, approximately $45 \%$ of Somali Internally Displaced Persons (IDP) households reported food consumption below subsistence levels, and $80 \%$, below recommended levels. It is no surprise that IDP populations report lower consumption levels. IDPs face significant hardship that hinders their potential for generating adequate livelihoods, such as experiencing the loss of a breadwinner, not having any productive assets, or having fallen victim to violence. Indeed, IDPs have much less control over their own livelihoods, employment opportunities are scarce within camps, and a large part of their consumption is provided for through aid by NGOs and international organizations.

Yet, there are also reasons that indicate that the low levels of consumption might be due, at least in part, to misreporting. First, very low levels of consumption are associated with high rates of mortality due to starvation. The observed mortality rates among IDPs, however, does not indicate that mortality increased due to starvation across the country at such a scale. ${ }^{1}$ Second, non-IDP households that are statistically similar on observable characteristics report higher levels of consumption than IDP households. While IDPs and non-IDPs may have different opportunities to generate income, it is unlikely that IDPs do not smooth their resources to balance food and non-food consumption in a way that endangers their life. The vulnerability of the population increases the stakes for getting the data right: for policymakers designing programs to support IDPs, spurious data is either unusable or biased.

The potential for surveys to generate information that is systematically biased is well documented. A large body of research focuses on improving the accuracy of self-reported information collected in household surveys. ${ }^{2}$ In the context of IDPs, that respondents feel compelled

\footnotetext{
${ }^{1}$ Although data from the USAID led Famine Early Warning Systems Network (FEWS NET) suggest high level of malnutrition, evidence on mortality across the counties is mixed (FEWS NET 2018).

${ }^{2}$ There are a number of mechanisms through which the validity of self-reported information in surveys can be compromised. Some inaccuracies result from cognitive biases-for example, acquiescence or "yea-saying” (Bachman and O'Malley 1984; Hurd 1999), extreme responding
} 
to misreport is particularly relevant. Indeed, survey respondents in IDP camps may believe that their responses will influence the provision of humanitarian aid and will thus misreport consumption in an attempt to influence its distribution. If survey respondents are underreporting, the inaccuracies generated in the data are highly problematic. At best, it makes the data spurious and unusable. At worst, it could lead to misallocations of aid, from more vulnerable areas to less vulnerable areas, or from solutions emphasizing sustainability to immediate relief when immediate relief is unnecessary. Given this context, light touch adaptations to the design of the survey that prime the idea of honesty offer to make big improvements to the quality of the data and support provisions the data informs. ${ }^{3}$

\section{The Implementation}

The experiment included 4145 IDP and 781 non-IDP households across South Sudan in 2017 rolled out in mid to late 2017. To investigate whether consumption might be underreported by IDP populations, households were randomly exposed to a bundle of 'honesty primes.' The treatment had three components, which were simultaneously administered in one treatment arm (Fig. 1). These included an emphasis on the importance of accurate answers at the beginning of the survey, a short fictional scenario, which required passing judgment on the behavior of one of the characters, and additional questions to

(Cronbach 1946; Hamilton 1968), and question order bias (Sigelman 1981). Other inaccuracies emerge from conscious but not calculated behavior. Respondents may deliberately misreport information on sensitive subjects not to distort statistics but to maintain their reputation or to abide by political norms (Gilens et al. 1998; Rosenfeld et al. 2016). Some misreporting is purposeful. Individuals may misreport in a calculated fashion to increase earnings in a study context (Mazar et al. 2008) or to shape the results of the study if they believe that it will inform policy. It is not surprising that this problem might arise in the context of development aid, an area rife with perverse incentives (Bräutigam and Knack 2004; Cilliers et al. 2015).

${ }^{3}$ This chapter is a summary of Kaplan, Pape, and Walsh (2018, forthcoming), "Eliciting Accurate Responses to Consumption Questions Among IDPs in South Sudan Using "Honesty Primes", Policy Research Working Paper Series. The World Bank. 


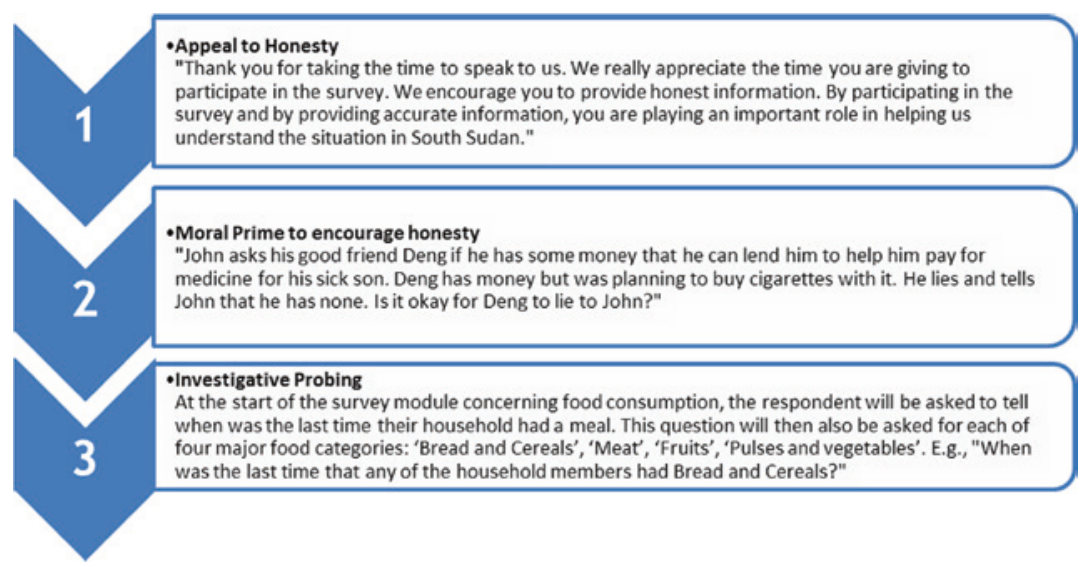

Fig. 1 Treatment Components (Source Authors' visualization)

determine the household's last meal, asking respondents to explicitly report whether or not they have eaten in the last week. ${ }^{4,5}$ While the former two targets intentional misreporting, the latter addressed classical measurement error. ${ }^{6}$ The bundle of primes addressed different psychological mechanisms:

1. Appeals to honesty: These are a standard tool in surveys to increase data accuracy that rely on respondents' preference for the social approval of the enumerator. ${ }^{7}$

2. Honesty primes: These bring the value of honesty to top of mind by asking the respondent to consider a fictional scenario in which honesty is relevant. If individuals feel they have a motivation to misreport, the honesty prime makes a competing motivation salient: to

\footnotetext{
${ }^{4}$ Mazar and Ariely (2006).

${ }^{5}$ One example of this is when individuals' beliefs regarding the consequences of lying affects their behavior. In a two-person experiment where one participant can increase her payoff by lying but at the expense to her counterpart, Gneezy (2005) finds that individuals' propensity to lie is sensitive to the costs it imposes on the other person.
}

${ }^{6}$ Rasinski et al. (2005) and Vinski and Watter (2012).

${ }^{7}$ Talwar et al. (2015). 
answer truthfully to sustain self-consistency. People make decisions on the basis of both external and internal reward systems: even when people have a material incentive to lie, their internal drive to protect their self-integrity may override. ${ }^{8,9}$

3. Investigative probing: This places a higher salience on the importance of getting answer to the question right. By asking for broader categories first, subsequent sub-categories are put under more scrutiny. Self-consistency is reinforced by relating to a longer recall period of seven days.

It is important to note that the treatment is not designed to directly elicit increases in reported consumption. Rather, the intention is to bring the importance of honesty into focus during the interview. It is only through this mechanism-increases in honesty-that we should expect to indirectly see increases in consumption. Thus, ex-ante, we should not expect the treatment effects to be uniform across the consumption distribution.

Almost one-third of respondents (30.1\%) reported a calorie intake below the daily subsistence level of $1200 \mathrm{kcal}$ per day and the median per capita consumption was below the recommended calorie intake (1589 kcal per day). Conditioning on adult equivalents, the median shifted well above the recommended daily intake. However, a substantial part of the distribution, $16 \%$, still reported being below the subsistence level and $40 \%$ reported being below the recommended daily intake. ${ }^{10}$ As with the number of consumption items, the graph indicates that there was a slight shift in the reported consumption among the treated, with respect to very low consumption levels.

\footnotetext{
${ }^{8}$ Mazar and Ariely (2006).

${ }^{9}$ One example of this is when individuals' beliefs regarding the consequences of lying affects their behavior. In an two-person experiment where one participant can increase her payoff by lying but at the expense to her counterpart, Gneezy (2005) finds that individuals' propensity to lie is sensitive to the costs it imposes on the other person.

${ }^{10}$ Several respondents report overly high consumption levels, which far surpass conventional levels (>4000 kcal per day). Robustness checks take this issue into account by censoring the data at the extremes.
} 
Different dependent variables are specified because they have different implications for the respondent's scope of influence on their value. The impact of the 'honesty primes' on the total consumption value, both in terms of money and food intake, is of primary interest. Yet, they are second-order values that are calculated as a function of other variables, including consumption quantities and calories or prices that are in turn deflated. These variables are difficult for respondents to falsify because of the intense mental computation required. The consumption quantity in kilograms is a more direct measure of the quantity consumed as expressed by the respondent and may lead to more accurate estimation of the impact of the 'honesty primes.' Finally, counting the number of items may lead to an even more accurate measure, since the variable is not cleaned and is taken at face value. Furthermore, omitting an item is the easiest and quickest way for respondents to reduce the value of the household's consumption. ${ }^{11}$

\section{Key Results}

There is a small difference in reported consumption on average between the treatment and control group. The consumption levels shown in Fig. 2 shows a slight difference in consumption between IDP households in the treatment and control groups, though this is apparent only at lower levels of consumption, below SSP 400. In contrast, the distribution of consumption across the two groups matches much more closely for the non-IDP population. The distribution of the number of items displays a similar pattern, though the effect is also faint (Fig. 3). Again, a difference is not visible in the non-IDP population. The number of observations for the non-IDP population is much lower than for the IDP population, and the variance of the distribution is expected to be much greater.

If respondents are deliberately misreporting, those misreporters are likely to be doing so at low consumption levels (e.g., it is more likely to

\footnotetext{
${ }^{11}$ Note that the number of consumption items is not reported at a per-capita level as it does not increase proportionally with household size.
} 


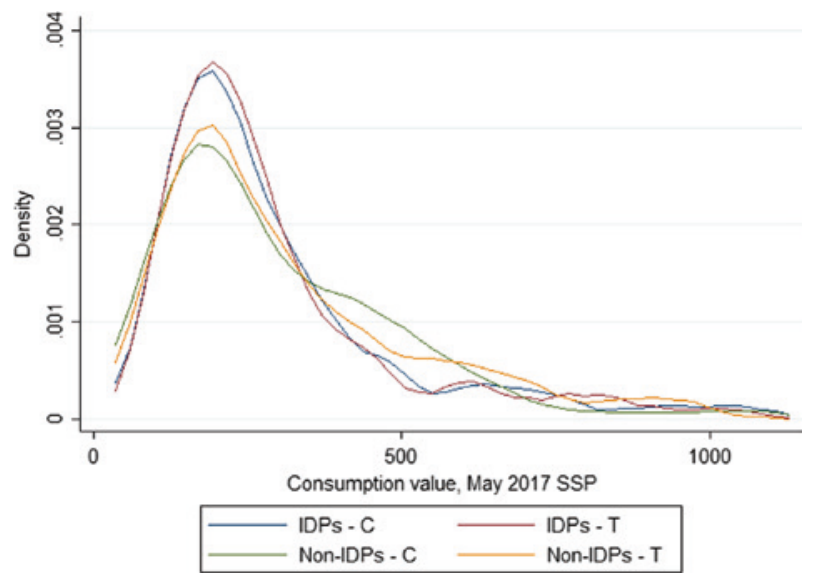

Fig. 2 Consumption distribution by population and treatment (Source Authors' calculations using HFS 2017, IDPCSS 2017 and CRS 2017)

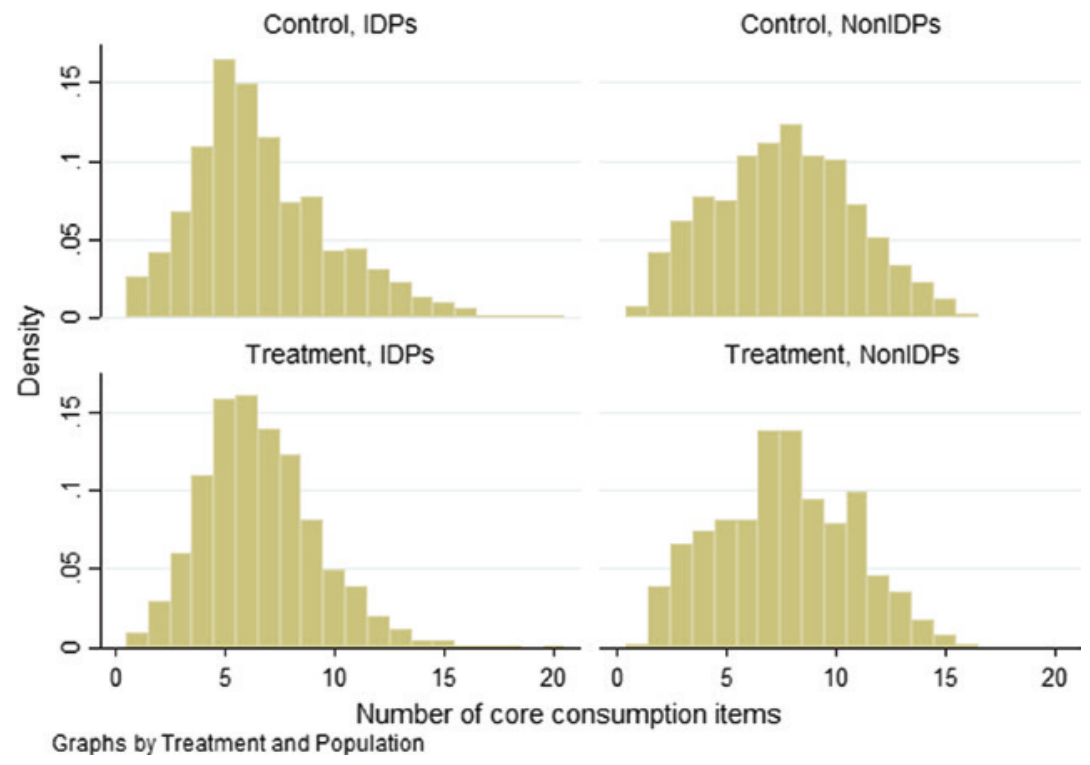

Fig. 3 Number of items consumed by population and treatment (Source Authors' calculations using HFS 2017, IDPCSS 2017 and CRS 2017) 
be the case that a small number of respondents are significantly underreporting, rather than a large number of people underreporting by a just a little bit). Given the treatment is not designed to increase reported consumption levels per se, but rather to invoke honesty, it should affect only those people who are misreporting. Hence, heterogenous treatment effects across different household consumption levels (quantiles) test the validity of 'honesty primes.' ${ }^{12}$ Figure 4 depicts priming effects across different consumption levels for the four outcome measures of interest. ${ }^{13}$ The priming significantly increases reported consumption among lower consumption levels, but not for medium and higher consumption levels. Significant treatment effects mainly influence the reported number of consumption items and the quantities in kilograms. Monetary and caloric consumption measures are not as strongly affected. The latter might also be less susceptible to deliberate misreporting as they depend in part on variables over which the respondent has no control (calories per item; deflators).

The priming has stronger effects among the more vulnerable IDPs. The non-IDP subsample is used to assess the robustness of our main results as we would expect a less significant priming effect among the non-IDPs. Results in Fig. 5 indicate less significant effects, corresponding to the hypothesis that 'honesty primes' are more effective among more vulnerable IDPs. ${ }^{14}$ This corresponds to adverse/perverse incentives in foreign assistance settings. Specifically, when IDPs are exposed more intensively to development aid, they may more likely signal their 'neediness' or provide socially desirable answers to signal their 'worthiness' for assistance.

Four dichotomous indicators are used to assess whether the priming shifts a significant share of respondents above certain reporting

\footnotetext{
${ }^{12}$ One might be concerned that honesty primes affect the consumption level of households and, thus, shift the household to another comparison group. Due to the theoretical expectation that treatment effects occur at lower levels of household consumption and are 'light-touch', treatment and control group should still be comparable.

${ }^{13}$ Figure 4 provides a band of the statistical $95 \%$ confidence interval of the estimate. Thus, if the confidence band does not cross zero, there would be a $5 \%$ chance of indicating significant effects, while the 'true' effect would be zero.

${ }^{14}$ For example, Cilliers et al. (2015) or Bräutigam and Knack (2004).
} 

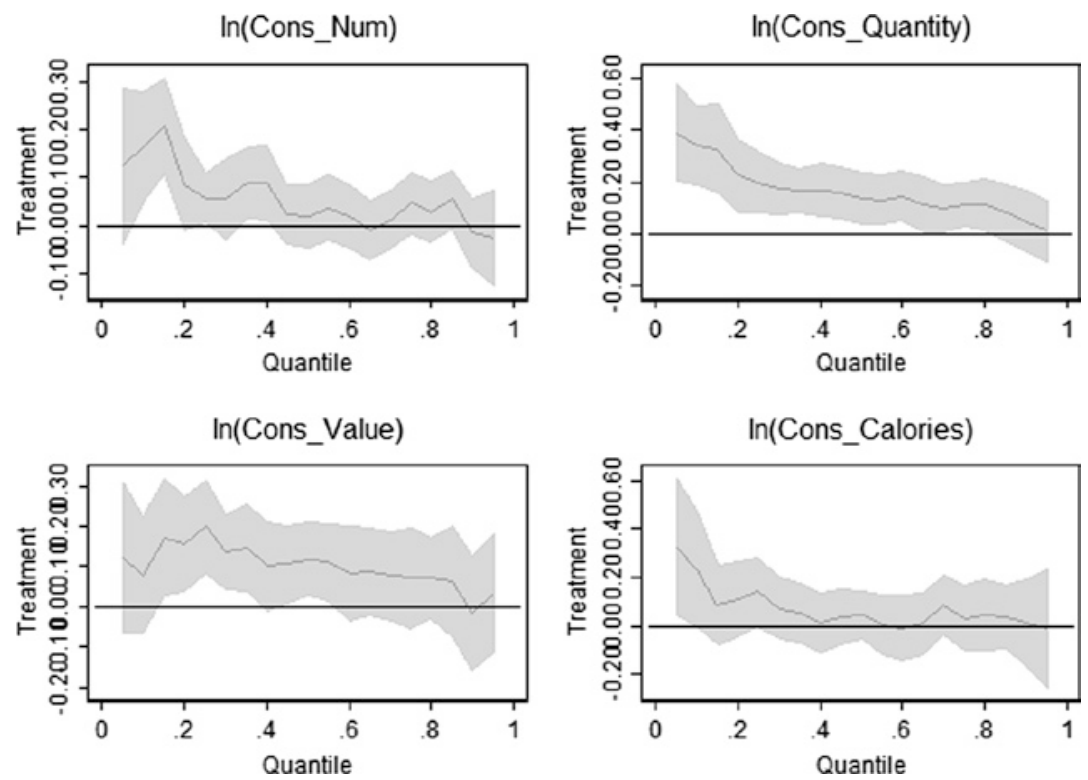

Fig. 4 Treatment effects across quintiles (IDPs) (Source Authors' calculations using HFS 2017, IDPCSS 2017 and CRS 2017. All regressions use clustered robust standard errors [White 1980]. Confidence bands refer to the $95 \%$ confidence interval. Consumption quantities, values, and calories are used in per-adult equivalent terms. The regression framework is introduced in the appendix. No sampling weights are used as 'honesty primes' are expected to affect, specifically, the extremes of the distribution and the average treatment effect is not a priori of interest)

thresholds. The indicators are equal to one if (i) the respondent household surpasses the caloric subsistence level of $1200 \mathrm{kcal}$ or (ii) the recommended level of caloric intake of $2100 \mathrm{kcal}$. Two further dummies are created at (iii) $66.66 \%$ and (iv) $100 \%$ of a normalized poverty line, which is scaled by the fact that only core consumption items were assessed consistently across all surveys. Although the coefficients are mostly positive, only two coefficients turn significant in columns (2) and (3) (Table 1). The results stress the positive effect of the primes, where seven percent more respondent households would have reported above the recommended daily calorie intake level. However, only certain population strata are affected. 

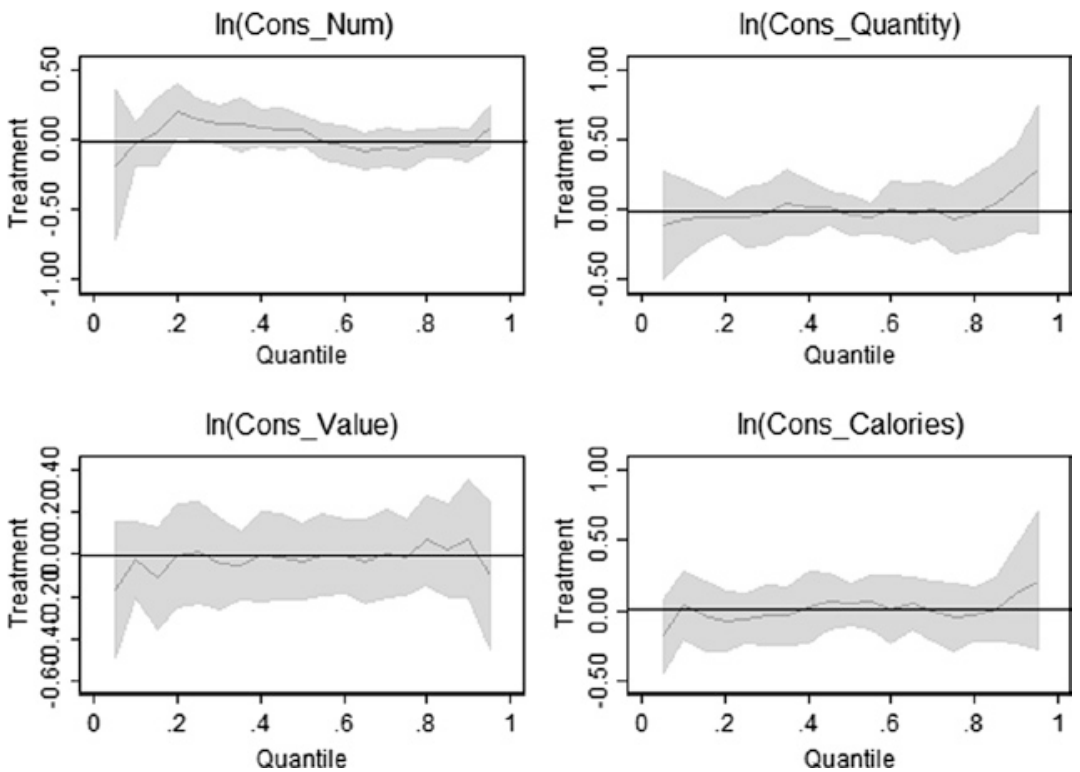

Fig. 5 Treatment effects across quintiles (non-IDPs) (Source Authors' calculations using HFS 2017, IDPCSS 2017 and CRS 2017. All regressions use clustered robust standard errors [White 1980]. Confidence bands refer to the $95 \%$ confidence interval. Consumption quantities, values, and calories are used in peradult equivalent terms. The regression framework is introduced in the appendix. No sampling weights are used as 'honesty primes' are expected to affect, specifically, the extremes of the distribution and the average treatment effect is not a priori of interest)

Table 1 Results using poverty thresholds

\begin{tabular}{lllll}
\hline & $(1)$ & $(2)$ & $(3)$ & $(4)$ \\
\cline { 2 - 5 } & $>1200 \mathrm{kcal}$ & $>2100 \mathrm{kcal}$ & $\begin{array}{l}>(2 / 3) \text { poverty } \\
\text { line }\end{array}$ & $\begin{array}{l}\text { >poverty } \\
\text { line }\end{array}$ \\
\hline Treatment & $0.010(0.027)$ & $0.069^{*}(0.037)$ & $0.063^{*}(0.037)$ & $0.029(0.036)$ \\
Observations & 3955 & 3955 & 3955 & 3955 \\
$\mathrm{R}^{2}$ & 0.067 & 0.098 & 0.118 & 0.135 \\
State fixed effects & Yes & Yes & Yes & Yes \\
Month fixed effects & Yes & Yes & Yes & Yes \\
Controls & Yes & Yes & Yes & Yes \\
Controls interacted & Yes & Yes & Yes & Yes \\
\hline
\end{tabular}

Source Authors' calculations using HFS 2017, IDPCSS 2017 and CRS 2017

Robust standard errors in parentheses: ${ }^{*} p<0.1,{ }^{*} p<0.05, * * * p<0.01$ 


\section{$4 \quad$ Lessons Learned and Next Steps}

Most measures to increase the accuracy of surveys assume that respondents want to report as accurately as possible. In many cases, this assumption is incorrect. This research offers novel and suggestive evidence that increasing the salience of honesty may increase survey accuracy, even if incentives to misreport exist. We find significant treatment effects for respondents most likely to be underreporting (those at lower levels), but no significant effects for those at higher levels who are unlikely to be underreporting. We find that the effects are stronger for outcome measures that can easily be manipulated (the number of consumption items) than for those that cannot easily be manipulated (the monetary consumption quantities).

The study underlying this chapter has two main limitations. First, while the experimental set-up allows for identifying a clean treatment effect, it can only compare the control group against an estimate of the 'true' rates of consumption. Without more objective data it is not possible to dismiss the possibility that the higher consumption levels reported in the treatment group are not true and subject to overreporting. The mortality rates among IDPs suggest that starvation is not occurring systematically across the country, but the precarious situation calls for further scrutiny. ${ }^{15}$ Before adjusting poverty estimates, a thorough comparison with more 'objective' data from administrative, anthropometric, or observational sources is needed. Second, the intervention is bundled. For this reason, it is impossible to isolate the causal mechanism affecting the observed changes in reporting. However, if classical measurement error would be affected, treatment effects of the primes should be uniform. In contrast, heterogenous effects across quantiles suggest that the targeting of intentional misreporting via the appeal to honesty and moral prime would be the driver of our results. More research, which unbundles these primes in different treatment arms or combines them with other survey tools can contribute to developing more durable solutions for data collection. Due to both the low

${ }^{15}$ FEWS NET (2018). 
costs in terms of money and survey time, the 'honesty primes' constitute a valuable supplement for surveys in contexts, where incentives for underreporting exist. Beyond fragile states, the primes could be also a possible survey extension if aid reliance is high (e.g., in Mali or Malawi) as indicated by our subsample analysis.

\section{References}

Bachman, J. G., and P. M. O’Malley. (1984). "Yea-Saying, Nay-Saying and Going to Extremes: Black-White Differences in Response Styles." Public Opinion Quarterly 48 (2): 491-509.

Bräutigam, D. A., and S. Knack. (2004). "Foreign Aid, Institutions, and Governance in Sub-Saharan Africa." Economic Development and Cultural Change 52 (2): 255-285.

Cilliers, J., O. Dube, and B. Siddiqi. (2015). "The White-Man Effect: How Foreigner Presence Affects Behavior in Experiments." Journal of Economic Behavior and Organization 118: 397-414.

Cronbach, L. J. (1946). "Response Sets and Validity." Educational and Psychological Measurement 6 (4): 672-683.

FEWS NET. (2018). Famine Early Warning Systems Network. Tratto il giorno March 22, 2018 da South Sudan Food Security Outlook-October 2017 to May 2018. http:/www.fews.net/sites/default/files/documents/reports/ SOUTH\%20SUDAN\%20Food\%20Security\%20Outlook_102017_0.pdf.

Gilens, M., P. M. Sniderman, and J. H. Kuklinski. (1998). "Affirmative Action and the Politics of Realignment." British Journal of Political Science 28 (1): 159-183.

Gneezy, U. (2005). "Deception: The Role of Consequences." American Economic Review 95 (1): 384-394.

Hamilton, D. L. (1968). "Personality Attributes Associated with Extreme Response Style.” Psychological Bulleting 69 (3): 192-203.

Hurd, M. D. (1999). "Anchoring and Acquiescence Bias in Measuring Assets in Household Surveys." Journal of Risk and Uncertainty 19 (1/3): 111-136.

Kaplan, Lennart Christian, Utz Johann Pape, and James Sonam Walsh. (2018, forthcoming). "Eliciting Accurate Responses to Consumption Questions Among IDPs in South Sudan Using 'Honesty Primes'." Policy Research Working Paper Series. The World Bank. 
Mazar, N., and D. Ariely. (2006). "Dishonesty in Everyday Life and Its Policy Implications." Journal of Public Policy \& Marketing 25 (1): 117-126.

Mazar, N., O. Amir, and D. Ariely. (2008). The Dishonesty of Honest People: A Theory of Self-Concept Maintenance. Journal of Marketing Research 45 (6): 633-644.

Rasinski, K. A., P. S. Visser, M. Zagatsky, and E. M. Rickett. (2005). "Using Implicit Goal Priming to Improve the Quality of Self-Report Data." Journal of Experimental Social Psychology 41 (3): 321-327.

Rosenfeld, B., K. Imai, and J. N. Shapiro. (2016). "An Empirical Validation Study of Popular Survey Methodologies for Sensitive Questions.” American Journal of Political Science 60 (3): 783-802.

Sigelman, L. (1981). "Question-Order Effects on Presidential Popularity." Public Opinion Quarterly, 199-207.

Talwar, V., C. Arruda, and S. Yachison. (2015). "The Effects of Punishment and Appeals for Honesty on Children's Truth-Telling Behavior." Journal of Experimental Child Psychology, 130: 209-217.

Vinski, M., and S. Watter. (2012). Priming Honesty Reduces Subjective Bias in Self-Report Measures of Mind Wandering. Consciousness \& Cognition 21 (1): 451-455.

White, H. (1980). A Heteroskedasticity-Consistent Covariance Matrix Estimator and a Direct Test for Heteroskedasticity. Econometrica 48 (4): 817-838. 
The opinions expressed in this chapter are those of the author(s) and do not necessarily reflect the views of the International Bank for Reconstruction and Development/The World Bank, its Board of Directors, or the countries they represent.

Open Access This chapter is licensed under the terms of the Creative Commons Attribution 3.0 IGO license (https://creativecommons.org/ licenses/by/3.0/igo/), which permits use, sharing, adaptation, distribution and reproduction in any medium or format, as long as you give appropriate credit to the International Bank for Reconstruction and Development/The World Bank, provide a link to the Creative Commons license and indicate if changes were made.

Any dispute related to the use of the works of the International Bank for Reconstruction and Development/The World Bank that cannot be settled amicably shall be submitted to arbitration pursuant to the UNCITRAL rules. The use of the International Bank for Reconstruction and Development/The World Bank's name for any purpose other than for attribution, and the use of the International Bank for Reconstruction and Development/The World Bank's logo, shall be subject to a separate written license agreement between the International Bank for Reconstruction and Development/The World Bank and the user and is not authorized as part of this CC-IGO license. Note that the link provided above includes additional terms and conditions of the license.

The images or other third party material in this chapter are included in the chapter's Creative Commons license, unless indicated otherwise in a credit line to the material. If material is not included in the chapter's Creative Commons license and your intended use is not permitted by statutory regulation or exceeds the permitted use, you will need to obtain permission directly from the copyright holder.

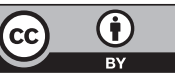

